\title{
Extinction of contextual fear and preference for signaled shock
}

\author{
MICHAEL S. FANSELOW \\ Rensselaer Polytechnic Institute, Troy, New York 12181
}

\begin{abstract}
Rats received signaled shock on one side of a shuttlebox and unsignaled shock on the other. After reaching a criterion preference for the signaled side, the experimental group was given Pavlovian extinction of contextual fear of the unsignaled side. The control group received equivalent exposure to a novel control chamber. Extinction of fear of the unsignaled side reduced the preference for signaled shock. This finding suggests that preference for signaled shock is mediated by contextual fear.
\end{abstract}

The rat finds a situation in which a painful electric shock is preceded by an explicit stimulus preferable to a situation in which the same stimulus is delivered unsignaled. This preference for signaled shock (PSS) has generated considerable experimental and theoretical attention. As the PSS literature has recently been subjected to several extensive reviews (Badia, Harsh, \& Abbott, 1979; Fanselow, 1980; Hymowitz, 1979), I will not attempt to review it here. Rather, the present paper will report on an experiment that tests a straightforward prediction from the most recent model of PSS, the contextual-fear hypothesis of Fanselow (1980).

Fanselow (1980) points out that when shock is signaled by some stimulus, modern theories of Pavlovian conditioning (e.g., Rescorla \& Wagner, 1972) lead us to expect that less fear would be conditioned to contextual stimuli than if the shocks were unsignaled (Baker, 1977; Baker \& Mackintosh, 1979; Odling-Smee 1975, 1978; Rescorla, 1972). The contextual-fear hypothesis of PSS adds only one simple performance rule to these Pavlovian principles: Rats withdraw from the contextual stimuli that elicit the most fear.

As a test of the contextual-fear hypothesis, Fanselow (1980) allowed rats to choose between a place in which a brief signal was negatively correlated with shock and a place in which the same shock was delivered but no signals were presented. According to the RescorlaWagner (1972) model, such a negatively correlated signal should increase contextual fear relative to the unsignaled-shock context, and, consistent with the contextual-fear hypothesis, the rats chose the unsignaledshock condition.

The negatively correlated cue provided information about shock-free time; so both the information hypothesis (D'Amato \& Safarjan, 1979) and the safety signal

This research was conducted in the laboratory of Robert C. Bolles while the author was a graduate student at the University of Washington. The author would like to thank J. Stewart for her help in running the animals. Address any correspondence to: Michael S. Fanselow, Psychology Department, Rensselaer Poly technic Institute, Troy, New York 12181. hypothesis (e.g., Badia \& Culbertson, 1972) predict a preference for the situation in which the negatively correlated cue occurred. Since the negatively correlated cue situation provided no information temporally accurate enough for the timing of a shock-modulating preparatory response, the preparatory response hypothesis (Perkins, 1968) predicts that the animals should find the negatively correlated signal situation and the unsignaled situation equally aversive. So, this aversion to the place at which the negatively correlated signal occurred, while supporting the contextual-fear hypothesis, runs contrary to predictions made by these other formulations that are often invoked to explain PSS.

According to the contextual-fear hypothesis, any manipulation that influences contextual fear should have a predictable influence on PSS. One such manipulation is Pavlovian extinction of contextual fear. When an animal is exposed to frightening contextual stimuli, in the absence of shock, contextual fear undergoes extinction; fear of the context is reduced (Bouton \& Bolles, 1979b; Dweck \& Wagner, 1970). Since, according to the contextual-fear hypothesis, rats prefer signaled shock because contextual fear is greater in the unsignaledshock situation than in the signaled-shock situation, reduction of contextual fear in the unsignaled-shock situation, via contextual extinction, should reduce the preference.

To test this prediction of the contextual-fear hypothesis, rats were given a choice of signaled shock on one side of a shuttlebox and unsignaled shock on the other. When the rats reached a criterion preference for the signaled side, they were confined to the unsignaled side. Control rats, also trained to the same criterion, received an equivalent amount of confinement but in a novel chamber. Following this confinement period, the rats' side preferences were tested.

\section{METHOD}

\section{Subjects}

The subjects were eight adult lean (FA/-) Zucker male rats weighing between $350 \mathrm{~g}$ and $500 \mathrm{~g}$ at the start of the experi- 
ment. The subjects were housed individually and handled daily for at least 3 weeks before the experimental procedure began. The animals were maintained on a $12-\mathrm{h} / 12-\mathrm{h}$ day/night cycle, and the experiment was conducted during the "lights-on" portion of the cycle.

\section{Apparatus}

A $76 \times 20 \times 18 \mathrm{~cm}$ shuttlebox was used. One compartment of the box was painted with $2.5-\mathrm{cm}$-wide black and white vertical stripes and the other compartment had similar stripes $1 \mathrm{~cm}$ wide. The lid of the shuttlebox was clear plastic. A removable clear plastic partition was used to confine the subjects to the unsignaled-shock side of the shuttlebox during extinction. The grid floor consisted of $1-\mathrm{cm}$ stainless steel rods spaced $2.5 \mathrm{~cm}$ center to center. The grid floor was connected to a Grason Stadler shock generator/scrambler that provided a .75-sec 1.0-mA scrambled electric shock.

The 20-sec signal was the "clatter" produced by an electromechanical flip-flop switched 5 times/sec by an electromechanical multivibrator. The signal was $80 \mathrm{~dB}$ (linear scale, background $61 \mathrm{~dB}$ ). The signal provided frequencies in the range of $250 \mathrm{~Hz}$ to $8 \mathrm{kHz}$, with amplitudes above the background noise level. ${ }^{1}$

The novel confining chamber was a $24 \times 23 \times 20 \mathrm{~cm}$ brown Masonite box. One wall $(24 \mathrm{~cm})$, which constituted the door, was clear plastic.

\section{Procedure}

A rat was placed in the shuttlebox for a maximum of five daily 44-min periods for a maximum of 3 days. Each period contained 10 presentations of the shock. Shock was presented on a VT 240-sec schedule, with intershock intervals distributed irregularly between $580 \mathrm{sec}$ and $80 \mathrm{sec}^{2}$ For four of the animals, the wide-striped side was designated as the signaled side; the other four animals received signals on the thin-striped side. On the signaled side, the clatter was sounded for $20 \mathrm{sec}$ before delivery of the shock. On the unsignaled side, no signals were ever presented. Shuttling from the signaled side to the unsignaled side during a scheduled signal presentation resulted in the immediate offset of the signal, and crossing in the opposite direction had the opposite consequence. The rat could not affect delivery of the shock.

After a 44-min period expired, the rat was removed from the shuttlebox and the data were recorded. The rat was then placed on the side of the shuttlebox opposite from where it had been removed for the next $44-\mathrm{min}$ period. The rat received this treatment until it spent $75 \%$ of three consecutive periods on the signaled side.

The day after the rat reached its criterion, it was assigned to either the experimental or the control group. Experimental animals were given contextual-fear extinction training. This was achieved by confining them to the unsignaled side of the shuttlebox for five 44-min periods. The rat was picked up out of the unsignaled side and then replaced in it between periods. The control animals were confined to the novel confining chamber for an equivalent amount of time and given equivalent handling. No shocks or signals were presented to either group during extinction training.

On the day following extinction training, all the rats were given the same preference test. A rat was placed on one side of the shuttlebox and allowed to explore it freely for $5 \mathrm{~min}$. It was then removed from the shuttlebox and placed on the side of the box opposite to its initial placement for a second 5-min test.

\section{RESULTS}

The data of all animals are presented in Table 1. The animals in the experimental group reached the
Table 1

\begin{tabular}{ccccc}
\hline Subject & Condition & Side $^{*}$ & Periods** & Time $\dagger$ \\
\hline 1 & E & W & 4 & .66 \\
5 & E & T & 9 & .63 \\
7 & E & W & 10 & .62 \\
8 & E & T & 8 & .50 \\
2 & $\mathrm{C}$ & $\mathrm{T}$ & 3 & .71 \\
4 & $\mathrm{C}$ & $\mathrm{T}$ & 10 & .98 \\
6 & $\mathrm{C}$ & $\mathrm{W}$ & 6 & .75 \\
9 & $\mathrm{C}$ & $\mathrm{W}$ & 8 & .92 \\
\hline
\end{tabular}

Note $-E=$ experimental; $C=$ control. $\quad$ *Side on which signal appeared: $W=$ wide striped; $T=$ thin striped. **Periods to PSS criterion. TMean percent of time on the signaled side during the preference tests.

preference criterion in a mean of 7.75 periods (77.5 shock trials), which was not different from the controls, which reached the criterion in 6.75 periods $(67.5$ shock trials).

The percentage of time the animals spent on the signaled side during the two five-min preference tests did not differ. For each animal, the mean of the two tests was determined, and this mean is presented in the fifth column of Table 1 . The experimental animals spent $60 \%$ of their time on the signaled side, significantly less than the controls, which spent $48 \%$ of their time on the signaled side $[t(6)=4.76, p<.01]$. Note that there is no overlap between the experimental and control groups (Mann-Whitney $\mathrm{U}=0, \mathrm{p}<.05$ ).

\section{DISCUSSION}

The contextual-fear hypothesis states that PSS is a function of the difference between the contextual fear of the signaledand unsignaled-shock situations. Signaling the shock supposedly causes a reduction of contextual fear relative to the unsignaled context, and the magnitude of this difference determines PSS. By extinguishing contextual fear on the unsignaled side, the present experiment reduced the difference in contextual fear of the two sides, and consistent with the contextual-fear hypothesis, there was a reduction in the strength of the preference for signaled shock.

It should be noted that the information hypothesis (D'Amato, 1974), the safety signal hypothesis (Badia \& Culbertson, 1972; Seligman, 1968), and the preparatory response hypothesis (Marlin, Berk, \& Miller, 1978; Perkins, 1968), the theories most often provided for PSS, do not predict these results unless some additional post hoc assumptions are made. One advantage of the contextual-fear hypothesis over these earlier theories of PSS is its ability to make testable predictions, such as the one made here. This may be contrasted with the other three hypotheses, which lead to different predictions in the hands of different investigators (contrast Badia, Harsh, Coker, \& Abbott, 1976, with Safarjan \& D'Amato, 1978, or contrast Marlin, Sullivan, Berk, \& Miller, 1979, with D'Amato \& Safarjan, 1979, see Fanselow, 1980, for how the contextual-fear hypothesis handles these differences).

The present data join a growing body of literature that attests to the importance of contextual stimuli in the control of behavior (e.g., Baker, 1977; Bouton \& Bolles, 1979a, 1979b; Dweck \& Wagner, 1970; Fanselow, 1980, in press; Kremer, 1974; Odling-Smee, 1975, 1978; Pearce \& Hall, 1979; Rescorla, 1972; Sheafor, 1975; Siegel, 1977; Tomie, 1976; Wagner, 1976; 
Bouton, Note 1). When PSS was first discovered (Lockard, 1963), it presented a paradox to the traditional view of the signal as an aversive elicitor of fear and anxiety (Estes \& Skinner, 1941; Mowrer, 1939). The paradox was that if both the signal and the shock are aversive, why does the rat choose the signaledshock situation, with its two aversive stimuli, over the unsignaledshock situation with only one aversive stimulus? We now see that this paradoxical finding fits nicely into the mainstream of modern Pavlovian theory.

\section{REFERENCE NOTE}

1. Bouton, M. E. Role of contextual stimuli in the effect of US inflation following fear conditioning. Paper presented at the meeting of the Eastern Psychological Association, Hartford, Conn., April 1980.

\section{REFERENCES}

Badia, P., \& Culbertson, C. The relative aversiveness of signaled vs. unsignaled escapable and inescapable shock. Journal of the Experimental Analysis of Behavior, 1972, 17, 463-471.

Badia, P., Harsh, J., \& Аввотт, B. Choosing between predictable and unpredictable shock conditions: Data and theory. Psychological Bulletin, 1979, 86, 1107-1131.

Badia, P., Harsh, J., Coker, L. L., \& Аввotт, B. Choice and the dependability of stimuli that predict shock and safety. Journal of the Experimental Analysis of Behavior, 1976, 26, 95-111.

BAKER, A. G. Conditioned inhibition arising from a betweensessions negative correlation. Journal of Experimental Psychology: Animal Behavior Processes, 1977, 3, 144-155.

Baker, A. G., \& Mackintosh, N. J. Preexposure to the CS alone, US alone, or CS and US uncorrelated: Latent inhibition, blocking by context or learned irrelevance? Learning and Motivation, 1979, 10, 278-294.

Bouton, M. E., \& Bolles, R. C. Contextual control of the extinction of conditioned fear. Learning \& Motivation, 1979, 10, 445-466. (a)

Bouton, M. E., \& Bolles, R. C. Role of conditioned contextual stimuli in the reinstatement of extinguished fear. Journal of Experimental Psychology: Animal Behavior Processes, 1979, 5, 368-378.

D'Aмато, M. R. Derived motives. Annual Review of Psychology, 1974, 25, 83-106.

D'Amato, M. R., \& Safarjan, W. R. Preference for information about shock duration in rats. Animal Learning \& Behavior, 1979, 25, 83-106.

DWeck, C. S., \& W AGNer, A. R. Situational cues and correlation between CS and US as determinants of the conditioned emotional response. Psychonomic Science, 1970, 18, 145-147.

Estes, W. K., \& SkinneR, B. F. Some quantitative properties of anxiety. Journal of Experimental Psychology, 1941, 29, $390-400$.

FAnSELOW, M. S. Signaled shock-free periods and preference for signaled shock. Journal of Experimental Psychology: Animal Behavior Processes, 1980, 6, 65-80.

FANSELOW, M. S. Conditioned and unconditioned components of postshock freezing. Pavlovian Journal of Biological Science, in press.

Hymowitz, N. Suppression of responding during signaled and unsignaled shock. Psychological Bulletin, 1979, 86, 175-190.

KREMER, E. F. The truly random control procedure: Conditioning to static cues. Journal of Comparative and Physiological Psychology, 1974, 86, 700-707.
LOCKARD, J. S. Choice of a warning signal or no warning signal in an unavoidable shock situation. Journal of Comparative and Physiological Psychology, 1963, 56, 526-530.

Marlin, N. A., Berk, A. M., \& Miller, R. R. Modification and avoidance of unmodifiable and unavoidable foot shock. Bulletin of the Psychonomic Society, 1978, 11, 203-205.

Marlin, N. A., Sullivan, J. M., Berk, A. M., \& Miller, R. R. Preference for inform tion about intensity of signaled tailshock. Learning and Motivation, 1979, 10, 85-97.

Mowrer, O. H. A stimulus-response analysis of anxiety and its role as a reinforcing agent. Psychological Review, 1939, 46, 553-564.

Oduing-Smee, F. J. Background stimuli and the interstimulus interval during Pavlovian conditioning. Quarterly Journal of Experimental Psychology, 1975, 27, 387-392.

Oduing-Smee, F. J. The overshadowing of background stimuli by an informative $\mathrm{CS}$ in aversive Pavlovian conditioning with rats. Animal Learning \& Behavior, 1978, 6, 43-51.

Pearce, J. M., \& Hall, G. The influence of context-reinforcer associations on instrumental performance. Animal Learning \& Behavior, 1979, 7, 504-508.

Perkins, C. C., Jr. An analysis of the concept of reinforcement. Psychological Review, 1968, 75, 155-172.

RESCorla, R. A. Informational variables in Pavlovian conditioning. In G. W. Bower (Ed.), The psychology of learning and motivation: Advances in research and theory (Vol. 6). New York: Academic Press, 1972.

Rescorla, R. A., \& Wagner, A. R. A theory of Pavlovian conditioning: Variations in the effectiveness of reinforcement and nonreinforcement. In A. H. Black \& W. F. Prokasy (Eds.), Classical conditioning II: Current theory and research. New York: Appleton-Century-Crofts, 1972.

Safarjan, W. R., \& D'Amato, M. R. Variables affecting preference for signaled shock in a symmetrical changeover design. Learning and Motivation, 1978, 9, 314-331.

Seligman, M. E. P. Chronic fear produced by unpredictable electric shock. Journal of Comparative and Physiological Psychology, 1968, 66, 402-411.

She AFOR, P. J. "Pseudo conditioned" jaw movements of the rabbit reflect associations conditioned to contextual background cues. Journal of Experimental Psychology: Animal Behavior Processes, 1975, 1, 245-260.

Siegel, S. Morphine tolerance acquisition as an associative process. Journal of Experimental Psychology: Animal Behavior Processes, 1977, 3, 1-13.

Tомге, A. Interference with autoshaping by prior context conditioning. Journal of Experimental Psychology: Animal Behavior Processes, 1976, 2, 323-334.

Wagner, A. R. Priming in STM: An information-processing mechanism for self-generated or retrieval-generated depression in performance. In T. J. Tighe \& R. N. Leaton (Eds.), Habituation. Perspectives from child development, animal behavior and neurophysiology. Hillsdale, N.J: Erlbaum, 1976.

\section{NOTES}

1. Decibel readings were taken at a number of specific frequencies between $31 \mathrm{~Hz}$ and $16 \mathrm{kHz}$. The author will provide this information upon request.

2. The time before the first shock presentation in a period and the time after the last shock presentation in a period were not included in the calculation of the mean intershock interval.

(Received for publication November 24, 1980.) 